\title{
Erratum zu: Kopf
}

Die korrigierte Version des Kapitels ist verfügbar unter $>$ https://doi.org/10.1007/978-3-662-49288-8_2 


\section{Erratum zu:}

Kapitel 2 in: B. N. Tillmann, Atlas der Anatomie des Menschen,

>https://doi.org/10.1007/978-3-662-49288-8_2

Wir machen darauf aufmerksam, dass die jetzt zur Verfügung gestellte Fassung sich von der zunächst veröffentlichten Fassung unterscheidet. Ursache dafür ist eine Korrektur der Beschriftungen in der Abbildungen 2.150 a,b und Abbildung 2.151a,b. 